\title{
COMPETENCIAS DE GÉNERO Y CULTURA DEL TRABAJO EN UNA FEDERACIÓN
} COMPETENCIAS DE GENERO E CULTURA DE TRABALHO EM UMA
FEDERAÇ $\tilde{A O}$
GENDER COMPETENCES AND WORK CULTURE IN A FEDERATION http://dx.doi.org/10.1590/1807-0310/2017v29157579

Concepción Mimbrero Mallado Universidad Autónoma de Barcelona, Barcelona, España

Joilson Pereira da Silva

Universidade Federal de Sergipe, Aracaju/SE, Brasil

Leonor Cantera Espinosa

Universidad Autónoma de Barcelona, Barcelona, España

\section{RESUMEN}

En este manuscrito abordamos las competencias de igualdad de género en la implementación de la transversalidad de género en organizaciones. El objetivo de este artículo es analizar estas competencias y conocer su relación con la cultura del trabajo engendrada en una federación de asociaciones de Andalucía, España. Empleamos una metodología cualitativa desde un abordaje de la Psicología Social Discursiva, aplicando las técnicas de entrevista y de observación participante en ocho miembros de la organización. Los resultados muestran que las personas participantes presentan todas las competencias de igualdad de género (conocimiento, metodológica, participativa y personal) facilitando la aplicación del mainstreaming de género en la organización. Además, el reparto equitativo de tareas, la cooperación y la confianza mutua, favorece el aprendizaje de estrategias comunes y eficaces para la solución de problemas y estar alerta para detectar situaciones que amenacen el clima positivo organizativo y de género.

Palabras clave: competencias; igualdad; género; organizaciones; culturas del trabajo.

\section{RESUMO}

Neste manuscrito abordamos as competências de igualdade de gênero na implementação da transversalidade de gênero nas organizações. $O$ objetivo deste artigo foi analisar essas competências e conhecer sua relação com a cultura de trabalho produzida em uma federação de associações de Andaluzia, Espanha. Utilizamos uma metodologia qualitativa desde uma abordagem da Psicologia Social Discursiva, aplicando as técnicas de entrevista e de observação participante em oito membros da organização. Os resultados mostram que os participantes apresentam todas as competências de igualdade de gênero (conhecimento, metodológica, participativa e pessoal), facilitando a aplicação do mainstreaming de gênero na organização. Ademais, a divisão equitativa das tarefas, cooperação e a confiança mútua favorecem a aprendizagem de estratégias comuns e eficazes para a solução de problemas e estar alerta para detectar situações que ameaçam o clima positivo organizativo e de gênero.

Palavras chave: competências; igualdade; gênero; organizacionais; culturas de trabalho.

\begin{abstract}
This manuscript tackles the competences of gender equality in the implementation of gender mainstreaming in organizations. The aim of this article was to analyze these competences and know its relation to the work culture engendered by a federation of associations of Andalusia, Spain. We used a qualitative methodology from an approach of Discursive Social Psychology, applying the techniques of interviewing and participant observation in eight members of the organization. The results show that participants have all the competences of gender equality (knowledge, methodological, participative and personal) facilitating the implementation of gender mainstreaming in the organization. In addition, the equal sharing of tasks, cooperation and mutual trust, promotes learning of common and effective strategies to solve problems and be alert to situations that threaten the positive organizational climate and the gender.
\end{abstract}

Keywords: competences; equality; gender; organizations; work cultures. 


\section{Introducción}

El mainstreaming o la transversalidad de género (acordada en la IV conferencia internacional de la mujer en Beijing, 1995), se estableció como la estrategia más adecuada para la evolución de la aplicación del principio de igualdad entre mujeres y hombres en las políticas públicas. No obstante, numerosas aportaciones demuestran las carencias que persisten en las distintas formas en que se aplica el mainstreaming de género que se basan en diferentes modelos como el sueco, el holandés, el alemán, el italiano entre otros (Bustelo \& Lombardo, 2005; Biencinto \& González, 2010; Mimbrero, 2014). Estos estudios ponen en relieve que es necesario y urgente articular nuevos métodos que detecten los desequilibrios entre mujeres y hombres para poder formular soluciones orientadas al logro de la igualdad real y efectiva (Addabbo, Rodríguez, \& Gálvez, 2013; Gálvez, 2013; Reverter, 2008).

En elámbito de las organizaciones, las estrategias, las medidas o los planes de igualdad son instrumentos para implementar el enfoque de género. En este sentido, es necesaria la adquisición de competencias de los miembros de la organización para el diseño y la puesta en marcha de estas herramientas. El concepto de competencia empieza a usarse como resultado de las investigaciones de David McClelland en los años 70, en las que se identificaron las variables relacionadas con el desempeño en el trabajo, centrándose más en las características y comportamiento de las personas que desempeñaban los empleos que en las descripciones de las tareas y atributos de los puestos (Vargas, Casanova, \& Montanaro, 2001). A partir de las transformaciones económicas de los años 80 , Inglaterra, y posteriormente Estados Unidos, se consolida como país precursor del enfoque de competencia, haciendo de este una herramienta para la mejora de la eficiencia, pertinencia y calidad de la formación. Desde entonces, el enfoque de competencias ha suscitado un debate a nivel científico. Entre los posicionamientos críticos, diversos autores alertan sobre las consecuencias de instrumentalizar los conocimientos reforzando su utilitarismo (Nussbaum, 2011, 2012; Gauchet, 2009). Así, Gauchet (2009) argumenta que éste modelo se orienta a "reconstruir los diferentes ámbitos de la vida social según el modelo del mercado económico y en especial los dos espacios que más resistirían a sus pretensiones: la política y el conocimiento" (p. 164). Otras posiciones, aun juzgando el individualismo que define este modelo, sostienen que el nuevo conocimiento puede ser socializado en el entorno laboral, permitiendo su incorporación a las rutinas de trabajo (Olarte, 2012). En este artículo, defendemos que el enfoque de competencias nos ayuda a articular el enfoque de género en el plano del aprendizaje organizativo. Teniendo en cuenta que, la estrategia mainstreaming puede implementarse desde diversos modelos (Biencinto \& González, 2010), establecer un modelo de competencias como un sistema de medida nos permite visibilizar las desigualdades entre mujeres y hombres. Desde esta postura, superando concepciones individualistas, entendemos que existe aprendizaje organizacional por competencias cuando los aprendizajes individuales son compartidos en la organización, en un ciclo bidireccional. En este sentido, se entiende que existe aprendizaje organizacional cuando los modelos metales individuales se socializan en la organización y desencadenan una respuesta en este ambiente. Si esta respuesta influye en el proceso de aprendizaje individual, se pueden producir nuevas acciones individuales y colectivas (organizativas), que reinician el ciclo del aprendizaje como circuito doble (Olarte, 2012). De la misma forma, trasvasamos este aprendizaje del plano organizativo al plano social, que no económico. En nuestro caso, la instrumentalización de la competencia nos sirve para explicar cómo se extiende el aprendizaje a otros contextos en los que interactúa cada hombre y cada mujer, permitiendo su incorporación a otros escenarios de vida.

En las entidades del tercer sector de acción social, las previsiones en relación a la capacidad de sus miembros para implementar el mainstreaming de género han de tenerse en cuenta dadas las características de sus organizaciones. Por una parte, por la escisión entre trabajo remunerado y voluntario que caracteriza a estas entidades (Benlloch, 2007). Por otra parte, por la capacidad de estas entidades para mediar entre el sector público y la sociedad, para detectar y tratar las situaciones a la que el primero, no llega por lejanía institucional (Delgado, 2008). De este modo, para abordar la implementación del mainstreaming y la capacitación de las personas que lo aplican, entendemos que también es importante tener en cuenta otros factores estructurantes de la identidad organizativa y de sus miembros, como la etnicidad y la cultura del trabajo (Sabuco, 2004). Entre los aspectos relativos a la identidad organizativa, en las entidades del tercer sector, son importantes sus orígenes y trayectoria, así como su vinculación a alguna organización matriz. De entre el conjunto de elementos identitarios, la misión, visión y valores condensan la identidad de la organización (Medina, 2009), condicionando las culturas del trabajo. En este sentido, el concepto de culturas del trabajo, es planteado por Palenzuela (1995) como el

Conjunto de conocimientos teórico-prácticos, comportamientos, percepciones, actitudes y valores 
que los individuos adquieren y construyen a partir de su inserción en los procesos de trabajo y/o de la interiorización de la ideología sobre el trabajo, todo lo cual modula su interacción social más allá de su práctica laboral concreta y orienta su específica cosmovisión como miembros de un colectivo determinado (p. 13).

Sabuco (2004) profundiza en la relación del género con la Cultura del Trabajo. Se posiciona en que el género se articula con los otros dos factores estructurantes, la etnicidad y las culturas del trabajo de un modo inseparable, destacando el papel de ambos factores en la construcción de las representaciones sociales y autorrepresentaciones genéricas. Las culturas del trabajo suponen integrar las prácticas, los conocimientos, el conjunto de cosmovisiones y las orientaciones cognitivas derivadas, tanto de los procesos de trabajo específicos en los que se insertan los individuos, como de su posición en las relaciones sociales de producción. Asimismo, estas culturas emergendentrodeestos contextos, frutode las relaciones entre personas conformadas según el sistema sexogénero de la sociedad a la que pertenecen. Partiendo del enfoque relacional del género con las culturas del trabajo que plantea Sabuco (2004), Mimbrero (2014) define la cultura de género organizativa como aquellos elementos socialmente construidos en interacción directa e indirecta entre individuos que participan en la organización. Conjuntamente, como concepto deslindable de la cultura de género, define el clima de género como la percepción subjetiva que tiene la plantilla respecto a la igualdad de oportunidades entre mujeres y hombres, que será más o menos propicia para la consecución de metas personales. Percepciones que, determinan las relaciones y que a su vez, están mediadas por experiencias subjetivas (vividas dentro y fuera de la organización), demandas y expectativas creadas dentro de este marco relacional de género. Sobre la base de estos constructos, esta autora señala la noción de competencia de igualdad de género (partiendo de la agencialidad del sujeto) como instrumento transformador de la cultura organizativa y de género, enmarcándola en el contexto de la aplicación de la dimensión de género en las organizaciones. Para caracterizar estas competencias de igualdad de género (también llamadas competencias de género), Mimbrero (2014) se apoya en la propuesta de Bunk (1994) que describe la competencia de acción profesional como la manifestación de varias competencias (técnica, metodológica, social y participativa) puestas en juego para el desarrollo de la acción profesional y que todas ellas forman la indivisible competencia de acción. Las competencias técnicas son el dominio experto de la tarea y los conocimientos y destrezas necesarios para llevarla a cabo. Las competencias metodológicas, relacionadas con la capacidad de transferir el saber hacer a diferentes situaciones profesionales. Las competencias sociales, referidas a las habilidades de interacción social y comunicativas y las competencias participativas, referidas a la pertenencia a un grupo, a la toma de decisiones y la asunción de responsabilidades (González \& González, 2008). Así, Mimbrero (2014) adapta el significado de la competencia de acción al plano de las capacidades de acción de hombres y mujeres para la implementación del mainstreaming de género en las organizaciones. Esta autora caracteriza estas competencias en cuatro tipos, todas ellas necesarias y complementarias: conocimiento, metodológica, participativa y personal. (a) Competencia de conocimiento. No necesariamente van unidos a la formación (entendida ésta como posesión de títulos). Estos conocimientos permiten analizar de manera crítica el contexto en el que se desarrollan las relaciones, igualitarias o no, entre hombres y mujeres. Conocimientos que son, evidentemente, necesarios para aplicar la perspectiva de género al desempeño del puesto de trabajo y, por ende, a la organización. (b) Competencia metodológica. Es la capacidad para aplicar las competencias de conocimiento que se posee llevando a cabo procedimientos de resolución de problemas ante situaciones de discriminación o desequilibrios por razón de género existentes en la organización. (c)Competencia departicipación. Permite estar en alerta favoreciendo una actitud participativa y cooperativa ante situaciones de desigualdad entre mujeres y hombres que se observen o prevean en la organización. Facilitan la puesta en marcha de la competencia metodológica. (d) Competencia personal. Supondría introyectar la igualdad de género, haciendo propia la necesidad de vivir en contextos de equidad entre mujeres y hombres. Es entendida como la imagen que construida de sí mismo en relación a la posición que se mantiene dentro de la organización. Posibilita a los individuos condiciones de estrategias para reconocer las competencias de conocimiento, metodológica y participativa que posee.

En definitiva, las competencias de conocimiento en materia de igualdad de género abrirían el proceso de aprendizaje para logar implementar el mainstreaming y transformar la cultura de género en organizaciones no igualitarias. El dominio de esta materia facilita seguir el proceso en un plano más relacional. Es decir, adquiriendo competencias metodológica y participativa que les permita aplicar estos conocimientos en el contexto de interacciones sociales que emerge en las organizaciones. Incluso, en otros contextos en los que participan. La competencia personal, cerraría el ciclo del proceso de aprendizaje. Esta supone el 
auotorreconocimiento del propio cambio vinculado a la imagen genérica personal (alejada de determinismos biológicos) y al quehacer diario para la articulación del género en la organización y en otros escenarios sociales.

En este orden de las cosas, las preguntas que guían el estudio en el que se enmarca nuestro artículo son: ¿cómo las competencias favorecen la transversalización del género en la cultura organizacional?, y ¿cómo la cultura de trabajo organizacional favorece la adquisición de las competencias? A partir de estas preguntas, coincidiendo con el propósito del estudio del que parte este manuscrito, el objetivo general de este artículo fue observar las competencias de igualdad de género (conocimiento, metodológica, participativa y personal) en las personas trabajadoras de una federación española. Además, relacionar estas competencias con la cultura del trabajo engendrada en esta organización.

\section{Metodología de la investigación}

El estudio se desarrolló en una federación de asociaciones de Andalucía (España). Participaron la totalidad de las personas empleadas y el presidente de la federación (6 mujeres y 2 hombres). Las mujeres tenían edades comprendidas entre los 35 y los 46 años. Ocupaban puestos de personal técnico, especializadas cada una de ellas en diferentes áreas: gestión económica, formación, comunicación y diseño, coordinación, calidad y jurídica. Los hombres de 32 y de 52 años, técnico jurídico y presidente respectivamente.

Esta federación es una organización sin ánimo de lucro que actúa en el ámbito de las drogodependencias y la exclusión social. Desde su creación, su sede administrativa se encuentra en la ciudad de Sevilla. La estructura de la organización engloba tanto a Asociaciones, como a Federaciones Provinciales con presencia en todas las provincias andaluzas. En la actualidad, comprende a 101 Asociaciones y 7 Federaciones Provinciales. Desde el punto de vista organizacional, se trata de una organización privada en cuya estructura formal las actividades se agrupan por especialización (gestión económica, formación, comunicación y diseño, coordinación, calidad y jurídica). Actividades llevadas a cabo por personal remunerado - profesionales de la acción social -. El voluntariado, desarrolla su trabajo como miembros de la junta directiva. La Junta Directiva está compuesta por 11 hombres y 13 mujeres, de ellos la presidencia está formada por 3 hombres y 1 mujer. Es relevante señalar que el movimiento asociativo de drogodependencias tuvo en su origen como importantes protagonistas a mujeres, en este caso, a las madres contra la droga (Talego, Florido, Manjavacas \&, Reigada, 2007). De aquellas madres todavía quedan algunas con un compromiso vigente, pero muchas otras ya no están en estas entidades. Actualmente, los objetivos de esta federación son apoyar a las entidades federadas en el desempeño de su intervención cotidiana, contribuir a que las personas drogodependientes y sus familiares reciban la atención que necesitan y favorecer las condiciones sociales más adecuadas para que aquellas con más dificultades puedan desenvolverse en la sociedad. En relación con los objetivos, esta organización se encarga de visibilizar que tras la drogodependencia, se encuentran muchos casos de discriminación. Debido a ello, la federación ha concedido un interés especial a la aplicación del enfoque integrado de género, participando en acciones formativas, desarrollo de jornadas y estudios desde el año 2008 en materia de género y drogodependencias. En el año 2010 esta federación asume un fuerte compromiso con la igualdad de género que se materializa con la aprobación unánime del I Plan de Igualdad 2011-2015 en su Asamblea General. Nuestra investigación se sitúa en este contexto, en el que desarrollamos un diagnóstico de igualdad de género en la organización durante el año 2010 para el diseño de este plan. Las personas investigadoras no tenían ningún tipo de vínculo con la federación y el estudio fue diseñado en colaboración con la organización.

Utilizamos la observación participante y la entrevista como técnicas principales para la recogida de datos dentro de la metodología cualitativa (Goode \& Hatt, 1979) desde un abordaje de la Psicología Social Discursiva, dirigida a la comprensión social de los procesos psicológicos. Desde esta perspectiva, lo psicológico no se entiende como un producto de las mentes individuales, sino el resultado de la participación en dinámicas y procesos de intercambio. El objeto de estudio, por tanto, se localiza en la interacción de las partes (Garay, Íñiguez, \& Martínez, 2005).

Para la observación participante usamos notas de campo en las que registramos episodios significativos sobre prácticas y costumbres que observamos como consecuencia de los procesos de trabajo, la interiorización de la ideología de la organización y las relaciones entre los miembros de la federación. Esta observación se llevó a cabo durante los 3 meses que nos llevó la recogida datos. En las notas registramos fechas, participantes, espacio, materiales, juicios, expresiones y descripción de los episodios (evidencias en relación a la cultura del trabajo engendrada en la federación) que posteriormente se usaron en las entrevistas narrativas como ejemplos de interacción 
e identificación de los miembros con la organización (Flick, 2007).

La entrevista narrativa se empleó con objeto de registrar prácticas discursivas conducidas a través de un guión de preguntas abiertas para evaluar las competencias de género (conocimiento, metodológica, participativa y personal). No obstante, a pesar de que el guión se estructuró para vincular cada grupo de pregunta al análisis de una determinada competencia, las respuestas de las y los entrevistados podían conducirnos a la observación de varias competencias. Como argumenta Garay et al. (2005) "la Psicología Discursiva se orienta hacia el estudio de la manera en que los diversos temas psicológicos son conceptualizados en la conversación cotidiana y en los textos, y en cómo estos se ordenan interactivamente" (p. 07).

Para observar las competencias de conocimiento (en cuanto a si describen situaciones de desigualdad o discriminación por razón de género y argumentan que puedan tener un origen cultural) y si su adquisición ha estado condicionada por el contexto en el que se interrelaciona (familiar, social, organizacional), preguntamos sobre la historia de vida profesional. Al respecto, incluimos en el guión preguntas como la siguiente: ¿Qué condicionantes - familiares, profesionales, personales - han determinado que orientes tu trabajo a combatir situaciones de desigualdad y discriminación social y de género?

Para observar las competencias participativas y las competencias personales, pedimos que se posicionaran sobre algunos aspectos relacionados con el ámbito de la igualdad de género dentro y fuera de la organización con preguntas como: ¿Qué opinas sobre la normativa de igualdad entre mujeres y hombres, planes de igualdad, utilización de lenguaje no sexista, cuotas de representación o la Ley de matrimonios homosexuales? ¿Qué opinas sobre la presencia y representación de hombres y mujeres en puestos y cargos dentro de la federación? ¿Y sobre las relaciones entre mujeres y hombres de tu organización? ¿Y sobre tu propia situación y la de tus compañeros y compañeras en relación a aspectos como conciliación, oportunidades de promoción, bajas laborales, acoso sexual o por razón de sexo? En estas dos últimas cuestiones preguntamos sobre roles, relaciones de poder existentes, alianzas entre miembros y las dinámicas relacionales vinculadas al género, para indagar sobre la interacción en el discurso cotidiano (Garay et al., 2005). Para ello, se usaron episodios registrados en las notas de campo (prácticas relacionadas con la interacción cotidiana) como forma en que se aplicó la psicología discursiva al material empírico. Así, vislumbramos si la cultura del trabajo organizacional favorecía la adquisición de competencias.

Para observar las competencias metodológicas y profundizar en el conocimiento de las competencias participativas se incluyeron en el guión las siguiente cuestiones generales ¿Puedes describir posibles soluciones para combatir las desigualdades sociales de género existentes? ¿Has participado de alguna manera en la lucha para combatirlos? ¿Puedes plantear medidas para cubrir las necesidades de la organización que puedan reflejarse en el Plan de Igualdad de Oportunidades entre Mujeres y Hombres? En este caso, también se usaron como ejemplo determinados episodios registrados en el diario de campo.

Todas las personas participantes fueron informadas previamente sobre todo el proceso. Solicitamos la autorización firmada en un término de consentimiento libre y esclarecido con autorización para la grabación en audio digital. El material obtenido fue mantenido con diligencia y sigilo con el propósito de mantener el carácter de anonimato y confidencialidad con que se manejarían sus respuestas. Todo ello de acuerdo con lo previsto en las normativas que regulan la investigación con seres humanos.

\section{Resultados y discusión}

En este apartado presentamos los análisis de las entrevistas de acuerdo con las competencias de igualdad de género (conocimiento, metodológica, participativa y personal) planteadas por Mimbrero (2014). Unos resultados de categorías de análisis a priori que relacionamos con la cultura de trabajo engendrada en la federación. Los nombres que acompañan a los fragmentos de las entrevistas son ficticios para salvaguardar la identidad de las personas participantes.

\section{Competencia de conocimiento}

De acuerdo con Donoso-Vázquez y VelázquezMartínez (2013), el primer nivel de desarrollo de la conciencia de género lo situamos en la adquisición de elementos conceptuales que permiten obtener conocimiento nuevo aunque no lleve asociado un cambio de actitud. Proceso que se complementa con un nivel más avanzado como el que observan Bagard y Hyde (1991). Sus investigaciones demuestran cómo personas con formación en esta materia disponen de una visión de análisis crítico de la realidad, pudiendo discernir en ella situaciones en las que se da una discriminación entre hombres y mujeres. Es decir, a través de una perspectiva más multidimensional y 
relativista, frente a los enfoques discriminatorios y excluyentes.

Este ejemplo también se da en nuestro estudio, en el que las y los participantes son capaces de definir el contexto social actual en el que se enmarca su trabajo y de elaborar argumentos sobre situaciones en las que consideran que hay discriminación de género. Esta capacidad de análisis les hace percibir las diferencias en mujeres y hombres drogodependientes: "Las mujeres drogodependientes están mucho más puteadas, mucho más criminalizadas en el barrio, por la familia... Las mujeres están mucho peores vistas que los hombres drogodependientes, incluso por la familia" (Ana). "Casi no se encuentran mujeres drogodependientes que vengan acompañadas por una pareja que les ayuda ... Cuando vienen acompañadas por parejas, estos hombres son también toxicómanos" (Elena).

Sin embargo, el análisis de la situación a veces es ambiguo, debido a que el concepto de género es interpretado desde varias perspectivas. Se trata de confusiones en el uso de este concepto que lleva a las personas a cometer distintos tipos de error manifestándose de diferente forma (Izquierdo, 1994). Así, describen y opinan con imprecisión sobre situaciones de discriminación basadas en el género. La continua duda sobre la diferencia entre hombres y mujeres, se encuentra justificada por determinismos tanto biológicos como culturales: "Yo creo que el hombre quizá es más violento, o tiene más conflicto interior. Quizá por la misma naturaleza del hombre, que sea más conflictivo, y la mujer sea más estable... no lo sé" (Marta).

Trasladándolo al contexto de la organización, en la entrevista 1, la entrevistada comenta por qué hay más mujeres que hombres ocupando puestos en la federación: "Pues no sé, quizá por accidente. Además también suele haber más mujeres en las asociaciones, $y$ en el campo de lo social, y por probabilidad nos han cogido a nosotras..."

Además, el desconocimiento sobre algunos elementos conceptuales relacionados con la igualdad de género les lleva a malinterpretar conceptos fundamentales como el del feminismo. Diversos estudios demuestran que la compresión y aceptación de la ideología feminista viene en parte determinada por la formación en materia de género (Dabrowski, 1985; Donoso-Vázquez \&Velázquez-Martínez, 2013).

"No, no me considero feminista, me considero normal ... Yo creo que en la federación el problema de la igualdad no existe, ni ellas son feministas radicales $n i$ hay machismo, así que esta todo bastante igualitario" (Ramón). Una formación que también se adquiere en contextos informales de aprendizaje "yo esto no lo he aprendido sólo haciendo cursos, lo aprendes también en tu casa, con la gente que tratas a diario y que son de tu profesión" (Carmen).

Estos resultados nos conducen a pensar que los miembros de esta organización poseen competencias de conocimiento adquiridas en contextos formales y no formales de aprendizaje. Pero este conocimiento es insuficiente por lo que genera descripciones ambiguas sobe situaciones de desigualdad existentes dentro y fuera de la organización.

\section{Competencia metodológica}

La competencia metodológica la observamos cuando plantean soluciones para superar las desigualdades de género en la organización y la situación personal que viven las trabajadoras y los trabajadores como consecuencia de la cultura del trabajo engendrada en la federación. En relación a posibles soluciones para incluir en el plan de igualdad una trabajadora comenta: "Las medidas de conciliación existen aunque no estén escritas. Pero claro, cuantas más mejor. Aqui hay bastante flexibilidad, pero estas cosas es mejor escribirlas" (Eva).

Otra trabajadora, comenta sobre la promoción del uso de un lenguaje no sexista en la comunicación interna y externa de la organización:

Lo que hacemos es sensibilizar el trabajo que hacemos. Y reivindicar, opinar. ... El lenguaje... intentamos hacerlo bien y los textos lo cuidamos mucho. A ver, hay mucho que mejorar, eso también nos plantea mucho debate, pero en lo escrito lo cuidamos muchísimo. (Ana)

Además, estas actitudes se extrapolan a otros sistemas en los que interactúan. Donoso-Vázquez y Velázquez-Martínez (2013), también constata estos resultados entre alumnado universitario que ha sido formado en materia de igualdad de género. En este sentido, argumenta que adquieren capacidad para la elaboración de propuestas de cambio en la propia vida $y$ en los contextos en los que interaccionan.

En nuestro estudio, en relación al acceso de hombres y mujeres a recursos públicos en el ámbito de la drogodependencia una entrevistada comenta: "Sabemos que es distinto, que los recursos por ejemplo suelen ser por la mañana, sitios públicos y, claro, el drogodependiente hombre es más público. No están preparados para las mujeres" (Carmen).

No obstante, debido a la falta de conocimiento (competencias de conocimiento) que tienen en materia de género, la opinión sobre la implementación de 
medidas de igualdad en la federación y la percepción sobre el impacto que puedan generar también a veces son ambiguos, encontrándonos con declaraciones como las que siguen: "Hemos hecho algunos cursitos, pero realmente no sabes en qué consiste un plan de igualdad en la entidad, así q no sé realmente en que nos va a beneficiar (Carmen). "Supongo que sí, que va a hacer que tomemos conciencia de que hay determinadas cuestiones que no te das cuenta" (Juan). "A mi directamente no sé... vamos ... Hombre, todas las cosas nuevas, pues que beneficien a la entidad. Todo lo que aprenda siempre viene bien, y se puede aplicar" (Elena).

Amodo de síntesis, observamos que los miembros de la federación poseen competencia metodológica. Sin embargo, un mayor conocimiento en materia de igualdad de género les ayudaría a mejorar la aplicación de los mismos.

\section{Competencias de participación}

Las competencias de participación, permiten estar en alerta ante situaciones de desigualdad entre mujeres y hombres que se observen o prevean en la organización y facilitan la puesta en marcha de la competencia metodológica que les lleve a la acción para la transformación. En este sentido, observamos que las personas entrevistadas muestran temor ante un posible cambio de presidente al que atribuyen el fortalecimiento y mantenimiento de un clima de trabajo positivo entre mujeres y hombres. Así lo registramos en el diario de campo cuando en encuentros informales con las trabajadoras comentaban las mejoras producidas en la federación (en cuanto a las relaciones entre sus miembros), gracias al presidente. Cuando preguntamos sobre las medidas de conciliación que había promovido el presidente comentan: "Anteriormente, con el otro presidente... no tenía ningún tipo de flexibilidad. En ese momento era muy complicado plantear quejas al presidente, era más autoritario, totalmente" (Eva). "Por eso, si sería mejor que estuviera por escrito, por si viene también otro presidente, porque es mejor. Porque es que al final como ves que las demás tampoco se lo cogen, pues nadie se lo coge. Si estuviera por escrito sería mejor" (Sofía).

Estas competencias les permiten participar como agentes de igualdad dentro de los sistemas en los que interactúa. "Mi implicación es diaria, y dedicándole mucho tiempo. Entonces vas viendo cómo las cosas han ido cambiando y se ha ido transformando" (Juan).

Siguiendo con el estudio de Donoso-Vázquez y Velázquez-Martínez (2013), las autoras también constatan que la formación en igualdad de género, facilita la adquisición de un compromiso de participación para la transformación de una sociedad que se percibe como discriminatoria.

En general, las vidas de las personas que forman parte de nuestro estudio han estado vinculadas a ambientes que han favorecido una sensibilidad hacia estos temas. Cuando preguntamos a uno de los entrevistados sobre su motivación para participar en la lucha para combatir desigualdades de género: "Yo durante un tiempo estuve en un colectivo feminista, $y$ ahi ya me metieron caña y reflexioné sobre muchas cosas" (Ramón).

En definitiva, la interiorización de la ideología que identifica a la entidad y a otras organizaciones afines así como la cultura del trabajo que emerge en la federación facilita la adquisición de las competencias de participación (Mimbrero, 2014).

Valores como la cooperación, la reivindicación de la igualdad social, de los derechos humanos, del respeto a la diversidad, el altruismo, entre otros, favorecen una postura sensibilizada ante las situaciones de discriminación social, y por ende, de género. Posturas que, desde una conciencia crítica, predisponen para la acción, para poner en marcha actitudes para comprender, adaptarse, enfrentarse o resolver situaciones en los distintos contextos de inequidad en los que interactúan. Siguiendo a Colás y Jiménez (2006, p. 423), "la «conciencia» fácilmente conduce a la reflexión sin acción. ... La «conciencia crítica» facilita un análisis contextualizado de situaciones problemáticas, lo que permite a las personas transformar esa realidad. ... La transformación, por lo tanto, proviene de una perspectiva crítica". Cuando preguntamos sobre las relaciones entre los miembros de la federación una de las participantes comentó "Con todas tengo una afinidad especial, quedamos mucho fuera del trabajo. La junta directiva está formada por voluntario de todas las provincias... son personas muy comprometidas socialmente, y creen en lo que persigue este movimiento asociativo" (Ana).

\section{Competencia personal}

La capacidad de análisis observada en estas personas se vincula a los procesos de autorrepresentación, al reconocimiento subjetivo de su identidad como mujeres y hombres. Gracias a la competencia personal, entienden cómo se perpetúan los estereotipos de género a nivel social, haciendo una evaluación de su propia situación, ejemplo también 
detectado por Bagard y Hyde (1991). Este proceso es reconocido empíricamente por Giraldo y Colyar (2012), entendido como el paso de la adquisición de conceptos a una conciencia crítica, y de ahí al cuestionamiento personal sobre la internalización y reproducción de estereotipos de género. En nuestro estudio, las mujeres por ejemplo, reconocen que reproducen conductas asociadas al rol tradicional femenino, ya que estas han sido adquiridas en el propio núcleo familiar y otros contextos relacionales de aprendizaje no formales:

Tiendo yo a asignarme las tareas, lo de mi casa reconozco que es parte de culpa mía ... Es que una vez ya participé en unas jornadas, y me encantó ver $y$ darme cuenta de cosas que... y de los esquemas que tengo machistas que no me había dado cuenta. (Sofía)

El plan a mi personalmente no sé cómo me va a afectar.. bueno, aprenderé, porque quieras que no, yo de mi educación familiar tengo también conductas machistas muy arraigadas, y cuanto más se reflexione sobre esto pues mejor. (Eva)

Además, reconocen la necesidad de cambio actitudinal y profesional propio, vinculado a la integración del enfoque de género en la organización. Cuando preguntamos sobre si había participado de alguna manera para combatir los desequilibrios de género existentes en la sociedad, Juan nos comentó: "voy desarrollando algo por lo que luché a mediados de los 80, apuestas por una determinada cuestión, es una opción personal de cambio social" (Juan). En este sentido, las personas entrevistadas consideran necesario el aprendizaje formal en materia de género:

Supongo que si que va a hacer que tomemos conciencia de que hay determinadas cuestiones que no te das cuenta... supongo que sí que estaré más atento a ciertas cosas o cambiará mi percepción... tiene que haber cantidad de cuestiones que utilice en mi forma de actuar que quizá se contradicen con la teoría, y una vez que tenga conocimiento seguro que me doy cuenta. (Ramón)

A modo de resumen, observamos cómo los miembros de la organización poseen la competencia personal y que, gracias a ellas, son conscientes de la necesidad de adquirir competencias de conocimiento para integrar el enfoque de género en la entidad y trasladarlo a otros escenarios sociales en los que se relacionan. Para una mejor representación de los resultados, en la Tabla 1. mostramos las competencias observadas a través de ejemplos de fragmentos de entrevista.
Tabla 1. Ejemplos de fragmentos de las entrevistas para la observación de competencias

\begin{tabular}{|c|c|c|}
\hline $\begin{array}{c}\text { Competencia } \\
\text { observada }\end{array}$ & Ejemplo de pregunta & $\begin{array}{l}\text { Fragmento de } \\
\text { entrevista }\end{array}$ \\
\hline Conocimiento & $\begin{array}{l}\text { ¿Encuentras diferencias } \\
\text { entre hombres y mujeres } \\
\text { drogodependientes? }\end{array}$ & $\begin{array}{c}\text { “Las mujeres } \\
\text { drogodependientes } \\
\text { están mucho más } \\
\text { puteadas, mucho más } \\
\text { criminalizadas" (Ana) }\end{array}$ \\
\hline Metodológica & $\begin{array}{l}\text { ¿Sabrías cómo poner } \\
\text { en marcha el plan de } \\
\text { igualdad de género en la } \\
\text { organización? }\end{array}$ & $\begin{array}{l}\text { "Hemos hecho } \\
\text { algunos cursitos, pero } \\
\text { realmente no sabes } \\
\text { en qué consiste un } \\
\text { plan de igualdad en la } \\
\text { entidad" (Carmen) }\end{array}$ \\
\hline Participativa & $\begin{array}{l}\text { ¿Qué opinión te } \\
\text { merecen las medidas } \\
\text { de conciliación que } \\
\text { ha promovido el } \\
\text { presidente? }\end{array}$ & $\begin{array}{l}\text { "Por eso, si sería } \\
\text { mejor que estuviera } \\
\text { por escrito, por si } \\
\text { viene también otro } \\
\text { presidente" (Sofía) }\end{array}$ \\
\hline Personal & $\begin{array}{l}\text { ¿Has participado } \\
\text { de alguna manera } \\
\text { para combatir los } \\
\text { desequilibrios de } \\
\text { género existentes en la } \\
\text { sociedad? }\end{array}$ & $\begin{array}{l}\text { “voy desarrollando } \\
\text { algo por lo que luché } \\
\text { a mediados de los } \\
\text { 80, apuestas por una } \\
\text { determinada cuestión, } \\
\text { es una opción } \\
\text { personal de cambio } \\
\text { social” (Juan) }\end{array}$ \\
\hline
\end{tabular}

\section{Consideraciones finales}

Diversos estudios indican que los avances hacia la equidad de género en las organizaciones, suponen un logro para aquellos miembros que luchan por conseguir estos equilibrios (Bonder, 2012; Gálvez \& Modroño, 2011; Reverter, 2008). Sin embargo, significan una amenaza para aquellas personas que buscan normalizar el status quo desde su situación de privilegio. No obstante, estas posturas no las interpretamos como monolíticas, ni tampoco tendrían que asociarse a posturas más o menos favorables, dado que dependen del contexto. Es por ello que presentar la realidad que viven mujeres y hombres (dentro y fuera de su organización) como realidades no estáticas puede resultar amenazante; mientras que entenderla como estable permite mantener el status quo. Indagar en las subjetividades y en los elementos dinámicos que conforman la cultura organizativa puede generar resistencias en contextos de desigualdad (Castells, 2003).

En nuestro estudio, encontramos que las personas que conforman la organización están sensibilizadas en materia de igualdad de género. Por ello, otorgan un valor fundamental a los cambios en la cultura del 
trabajo y de género. Pero en un afán por mejorar la situación, aparecen disfunciones que obstaculizan las transformaciones. En este sentido, las competencias de igualdad de género que observamos en la muestra nos permiten averiguar dificultades que puede mostrar la organización de cara a lograr la aplicación del mainstreaming.

En general, los resultados arrojan que las personas trabajadoras de la organización poseen todas las competencias de igualdad de género. Sin embargo, necesitan un mayor conocimiento y manejo de conceptos básicos del enfoque de género (competencia de conocimiento). Observamos que, si bien interpretan la realidad desde esta perspectiva gracias al aprendizaje adquirido en entornos formales y no formales, lo hacen de forma ambigua y a veces errónea.

La identificación con la entidad ha favorecido el desarrollo de estas competencias. La interiorización de los valores que persigue la entidad desde sus orígenes, que tuvo como protagonistas madres contra la droga, ha facilitado que el personal de la federación posea un compromiso social y personal con la igualdad en la sociedad y en la propia organización (competencia personal). Este compromiso les ha llevado a desarrollar estrategias para convertirse en verdaderos agentes para el cambio social (competencia participativa).

Además, la cultura del trajo engendrada en la organización les permite mantener su grado de autonomía profesional (necesidad de trabajar en equipo, de depender de otras personas, de otros departamentos para tomar decisiones y actuar de la manera más conveniente) así como tolerar los cambios que supone la asunción de un nuevo enfoque de trabajo: el enfoque integrado de género (competencia metodológica).

Igualmente, poseer estas competencias les lleva a reflexionar sobre las relaciones de género en la propia organización, siendo capaces de identificar los factores internos y externos que generan conflicto para el personal trabajador. Sirva de ejemplo las generadas por la propia cultura del trabajo en la que valores como el altruismo y el compromiso con el trabajo desde la militancia tiene una especial presencia. Este aspecto genera un doble efecto sobre las personas trabajadoras. Por una parte, genera estrés, sobrecarga de trabajo y malestar por el sentimiento de culpa que entraña la escisión entre trabajo voluntario y trabajo remunerado. Por otra parte un sentimiento de pertenencia a la entidad que les reconforta por el hecho de sentirse partícipe del compromiso con la igualdad como valor y prioridad en nuestra sociedad.
A la par, la cultura de trabajo favorece un buen clima de género en la organización, en la que el reparto de tareas, la cooperación y la confianza mutua, les permite desarrollar estrategias comunes y eficaces para la solución de problemas y les permite estar en alerta para detectar situaciones amenazantes.

El estudio presenta algunas limitaciones. La metodología aplicada a una sola organización implica que los resultados apenas pueden ser generalizables a entidades a otras entidades de tamaños, estructuras y ámbitos organizativos similares.

Pese a ello, los resultados de nuestra investigación generan un impacto social y en las organizaciones en la medida en que, permite reconocer las capacidades que son necesarias para aplicar el mainstreaming a los sistemas organizacionales en relación con sus culturas del trabajo. Igualmente, facilita el reconocimiento de estas capacidades entre los miembros de una organización para diagnosticar la situación en relación con la implementación de la transversalidad de género. Por ende, favorece el diseño estrategias para articular la dimensión de género desde un enfoque de competencias.

Además, son relevantes desde un punto de vista académico. Por una parte, contribuye a profundizar en el constructo de Mimbrero (2014) sobre las competencias de igualdad de género. En este sentido, nuestro estudio demuestra empíricamente la existencia de estas competencias y sus características en relación con aspectos de la cultura del trabajo organizativa. Por otra parte, supone contar con nuevos indicadores científicos para evidenciar las capacidades que pueden favorecer culturas y climas de género igualitarios.

En cuanto al impacto social y político, el estudio demuestra que estas competencias pueden adquirirse en entornos de aprendizajes formales y no formales. Además, pueden extrapolarse a otros contextos en los que las personas interactúan y no sólo dentro de una organización. Así, reconocemos que los resultados pueden ayudar a plantear intervenciones y soluciones políticas orientadas a sensibilizar y capacitar a los miembros de una sociedad. En este sentido, construir agentes de cambio que combatan las desigualdades que persisten entre mujeres y hombres más allá del ámbito organizativo.

\section{Referencias}

Addabbo, T., Rodríguez Modroño, P., \& Gálvez Muñoz, L. (2013). Gender and the Great Recession: Changes in labour supply in Spain. Universitá di Modena Reggio Emilia. DEMB Working Paper Series, 10, 1-28. Recuperado de http:// merlino.unimo.it/campusone/web_dep/wpdemb/0010.pdf 
Bagard, A. \& Hyde, J. S. (1991). Women's studies: A study of feminist identity development in women. Psychology of Women Quarterly, 15(2), 181-201.

Benlloch, P. (2007). Panorama de las relaciones laborales en el tercer sector. Revista española del tercer sector, 7, 131-163.

Biencinto, N. \& González, Á. (2010). La Transversalidad de género: métodos y técnicas. Sevilla: Instituto Andaluz de la Mujer.

Bonder, G. (2012). Fundamentos y orientaciones para la integración del enfoque de género en políticas, programas $y$ proyectos. (Cuadernos del Área Género, Sociedad y Políticas). Argentina: FLACSO.

Bunk, Gerhard P. (1994). La transmisión de las competencias en la formación y el perfeccionamiento de profesionales en la RFA. Revista Cedefop, 1, 8-14

Bustelo, M. \& Lombardo, E. (2005). "Mainstreaming de género y análisis de los diferentes 'marcos interpretativos' de las políticas de igualdad en Europa: el proyecto MAGEEQ". Aequalitas: Revista jurídica de igualdad de oportunidades entre mujeres y hombres, 17, 15 -26.

Castells, M. (2003). La era de la información: Economía, sociedad y cultura. El poder de la identidad (Vol. 2). Madrid: Alianza Editorial.

Colás, P. \& Jiménez R. (2006). Tipos de conciencia de género del profesorado en los contextos escolares. Revista de Educación, 340, 415-444.

Dabrowski, I. (1985). Liberating the "deviant" feminist image though education. Social Behavior \& Personality, $13,73-81$.

Delgado, L. (2008). El papel del tercer sector en las políticas de igualdad. Revista española del tercer sector, 8, 89-107.

Donoso-Vázquez, T. \& Velázquez-Martínez, A. (2013). ¿Por qué una propuesta de formación en perspectiva de género en el ámbito universitario? Profesorado, Revista de currículum y formación del profesorado, 17(1), 71-88. Recuperado de http://www.ugr.es/local/recfpro/rev171ART5.pdf

Flick, U. (2007). Uma introdução à pesquisa qualitativa. Porto Alegre: Bookman.

Gálvez Muñoz, L. (2013). Una lectura feminista del austericidio. Revista de economía crítica, 15, 80 -110.

Gálvez Muñoz, L. \& Rodríguez Modroño, P. (2011). La desigualdad de género en las crisis económicas. Investigaciones Feministas, 2, 113-132.

Garay, A., Íniguez, L., \& Martínez, L. M. (2005). La perspectiva discursiva en Psicología Social. Subjetividad y Procesos Cognitivos, 7, 105-130. Recuperado de http://dspace.uces. edu.ar:8180/xmlui/bitstream/handle/123456789/240/La\%20 perspectiva discursiva.pdf? sequence $=1$

Gauchet, M. (2009). Vers une société de l'ignorance? Le Débat, $156,144-166$.

González, V. \& González, R. M. (2008). Competencias genéricas y formación profesional: un análisis desde la docencia universitaria. Revista Iberoamericana de Educación, 47, 185-209. Recuperado de http://www.rieoei.org/rie47a09.htm

Goode, W. J. \& Hatt P. K. (1979). Métodos em pesquisa social ( $5^{\text {a }}$ ed.). São Paulo: Editora Nacional.

Giraldo, E. \& Colyar, J. (2012). Dealing with gender in the classroom: A portrayed case study of four teachers. International Journal of Inclusive Education, 16(1), 25-38.

Izquierdo, M. J. (1994). Uso y abuso del concepto de género. En M. Villanova (Comp.), Pensar las diferencias (pp. 31-53). Barcelona: Institut Catalá de la Dona.

Medina, J. (2009). Transparencia y buen gobierno en las ONGD. Revista Española Del Tercer Sector, 7(8), 93-113.
Mimbrero, C. (2014). Nuevo modelo diagnóstico de la cultura de género en la administración local y en el tercer sector de acción local. (Doctoral dissertation, University of Sevilla). Retrieved from http://fondosdigitales.us.es/tesis/tesis/2712/ nuevo-modelo-diagnostico-de-la-cultura-de-genero-en-laadministracion-local-y-en-el-tercer-sector-de-accion-social/

Nussbaum, M. (2011). Sense àsnim de lucre. Per qué la democarcia necessita les humanitats. Barcelona: Arcadia.

Nussbaum, M. (2012). Crear capacidades. Propuestas para el desarrollo humano. Barcelona: Paidos.

Olarte, J. C. (2012). Aprendizaje organizacional y proceso de consultoría. Voces y silencios. Revista latinoamericana de Educación, 3(1), 70-86.

Palenzuela, P. (1995). Las culturas del trabajo: Una aproximación antropológica. Sociología del trabajo, 24, 3-28.

Reverter, S. (2008). Sociedad civil, ciudadanía y género. $L a$ Aljaba Segunda época, 12, 33-52.

Sabuco, A. (2004). La Isla del Arroz Amargo. Sevilla: Blas Infante.

Talego, F., Florido, D., Manjavacas, J. M., \& Reigada, A. (2007). Desengancharse. Profesionalismo, Conversión, Ayuda Mutua y Solidaridad en los Problemas de Adicción. Sevilla: Bosque de Palabras.

Vargas, F., Casanova, F., \& Montanaro, L. (2001). El enfoque de competencia laboral: manual de formación. Montevideo: Cinterfor.

Submissão em: 10/12/2015

Revisão em: 09/10/2016

Aceite em: 24/10/2016

Concepción Mimbrero Mallado es doctora en Psicología Social y Máster en Estudios de género y desarrollo profesional por la Universidad de Sevilla (España).

Profesora del departamento de Psicología Social de la Universidad Autónoma de Barcelona (España). Sus líneas de investigación se centran en el estudio de las culturas de género en las organizaciones y en la empleabilidad social desde una perspectiva de género. Endereço: Universidad Autónoma de Barcelona, Facultad de Psicología, Edificio

B. Despacho B5/040. CP 08193-Bellaterra-Barcelona. E-mail: conchi.mimbrero@gmail.com

Joilson Pereira da Silva é doutor em Psicologia pela Universidade Complutense de Madri, Espanha. Mestre em Psicologia Social pela Universidade Federal da Paraíba.

Psicólogo e graduado em Estudos Sociais e Geografia

(UEPB). Professor Adjunto da Universidade Federal de

Sergipe e professor credenciado do Programa de Pósgraduação em Psicologia Social. Atua principalmente nos seguintes temas: educação, saúde e sexualidade, violência, bem estar e recursos psicossociais. E-mail: joilsonp@hotmail.com

Leonor Cantera Espinosa es doctora $(\mathrm{PhD})$ por la Universidad de Puerto Rico. Doctora en Psicología Social con Premio Extraordinario por la Universidad Autónoma de Barcelona (UAB). Profesora Titular de Psicología Social de la UAB. Coordinadora del grupo de investigación de la violencia en la pareja y el trabajo-VIPAT. Sus áreas de interés son: violencia, género, trabajo, comunidad. E-mail: leonor.cantera@uab.cat 